\title{
Prevalence of Dementia in the Torres Strait
}

Russell, Sarah.G ${ }^{1,2}$., Quigley, Rachel ${ }^{1,2}$., Thompson, Fintan ${ }^{3}$., Sagigi, Betty ${ }^{4}$. LoGiudice, Dina $^{5}$., Smith, Kate ${ }^{6}$., Pachana, Nancy ${ }^{7}$., Miller, Gavin ${ }^{2}$., \& Strivens, Edward ${ }^{1,2}$

1 College of Medicine and Dentistry, James Cook University, Cairns

2 Queensland Health, Cairns and Hinterland Hospital and Health Service, Cairns

3 Australian Institute of Tropical Health and Medicine, James Cook University, Cairns

4 Queensland Health, Torres and Cape Hospital and Health Service, Thursday Island

5 University of Melbourne Faculty of Medicine, Dentistry, and Health Sciences, Royal Melbourne Hospital

6 University of Western Australia

7 School of Psychology, University of Queensland

Corresponding author:

Sarah Russell

College of Medicine and Dentistry

Cairns Clinical School

$2^{\text {nd }}$ Floor, A Block

Cairns Hospital

Qld 4870

Sarah.Russel16@jcu.edu.au

Phone: 0421468492

\section{Acknowledgements:}

The authors wish to thank the residents of the Torres Strait who participated in this study and the staff at the primary health centres without whom the study would never have been completed. The team also wish to thank the members of the Key Stakeholder Working Group for their cultural guidance and expertise throughout the study.

The project was funded by a three-year NHMRC project grant (APP. 1106175).

This is the author manuscript accepted for publication and has undergone full peer review but has not been through the copyediting, typesetting, pagination and proofreading process, which may lead to differences between this version and the Version of Record. Please cite this article as doi: 10.1111/AJAG.12878

This article is protected by copyright. All rights reserved 


\section{$\underline{\text { Statement of conflicts of interest }}$}

The authors declare no conflicts of interest

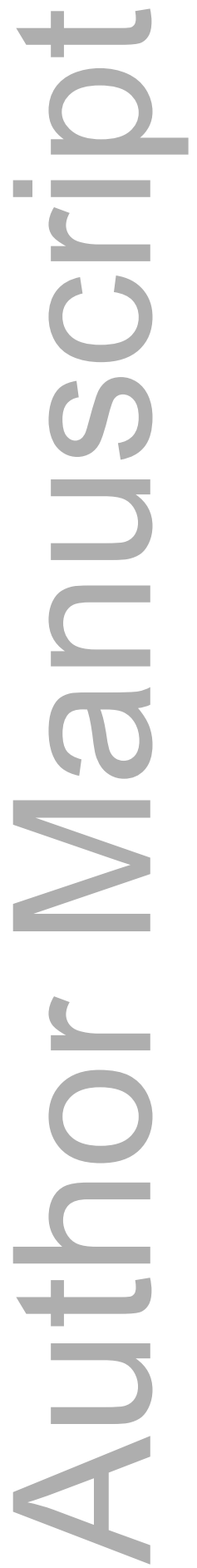

This article is protected by copyright. All rights reserved 
DR. KATE SMITH (Orcid ID : 0000-0003-4077-1996)

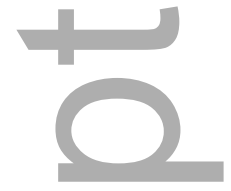

Article type : Research Article

Prevalence of Dementia in the Torres Strait
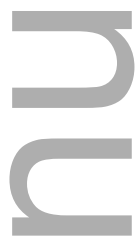

Abstract

\section{Objective}

To examine the prevalence of dementia and problems associated with ageing in the Torres Strait.

\section{Methods}

The study was conducted across all 18 island and 5 mainland communities in the Torres Strait and Northern Peninsula Area of Far North Queensland. Participants underwent a comprehensive health assessment and a Geriatrician assessment, which was used to establish consensus diagnoses.

\section{Results}

A total of 276 Torres Strait residents aged between 45 and 93 participated in the study. The prevalence of dementia in the sample was $14.2 \%$, which was 2.87 times higher than the wider Australian population.

\section{Conclusion}

Torres Strait Islander peoples share the increased risk of dementia seen in Aboriginal Australians compared to the wider community. This highlights the need for interventions to address this increased dementia risk for Aboriginal and Torres Strait Islander communities. 
$\underline{\text { Key words }}$

Alzheimer's Disease; Epidemiology; Geriatrics; Indigenous People; Vascular disease

\section{Introduction}

Dementia is a global challenge affecting an estimated 46.8 million people worldwide, with rates expected to double in high income countries and treble in low to middle income countries by $2050^{1}$. In Australia, where the number of people living with dementia is expected to exceed one million by $2058^{2}$, dementia is the second overall leading cause of death and the leading cause of death in females ${ }^{3}$. Whilst dementia risk increases with age, $6 \%$ of people are diagnosed under the age of $65^{2}$ and are considered as having Younger Onset Dementia. People living with Younger Onset Dementia often report a delay in obtaining a diagnosis and difficulty accessing appropriate respite and residential care ${ }^{4}$. They also face different challenges to older adults with dementia, with many still in the workforce or with dependant children ${ }^{4}$.

As life expectancy for Aboriginal and Torres Strait Islander peoples continues to rise ${ }^{5}$, an increased risk of dementia has been reported within Aboriginal communities. In a 2008 study, the prevalence of dementia in Aboriginal Australians aged 45 years and over living in the Kimberley region of Western Australia was $12.4 \%^{6}$, which was 5.2 times higher than the Australian population rate of $2.4 \%$ for the same age $\mathrm{e}^{7}$. When age standardised, the dementia prevalence ratio was largest for the 45-69-year-old group, at 26, reducing with age to 3.4 in the 80 and over group. This narrowing of dementia risk with age has been explained as a result of premature deaths and survivor bias. Increased risk and earlier dementia onset may reflect the cumulative impact of comorbid midlife chronic diseases ${ }^{6}$. A further $8 \%$ of those aged over 45 , and $13.4 \%$ of those aged over 65 , had objective evidence of cognitive decline but minimal functional impact, which has been described as mild cognitive impairment or 
Cognitive Impairment Not Dementia $(\mathrm{CIND})^{8}$. Although rates of CIND in Western communities vary greatly depending upon diagnostic criteria and assessment processes used, a recent systemic review estimated prevalence to be around 6.7\% in people aged 60-64 and over, increasing to $25.2 \%$ in those aged $80-84$ years $^{8}$. High rates in the Kimberley study are of particular concern, given CIND is a known risk factor for dementia ${ }^{8}$. Other dementia risk factors reported in the Kimberley study included older age, male gender, no formal education, stroke, epilepsy, head injury, poor mobility, falls, and incontinence ${ }^{9}$.

A threefold dementia risk has also been identified in Aboriginal people aged 60 and over living in urban and regional NSW communities ${ }^{10}$. In addition to age, head injury and stroke, this study identified social and whole of life span risk factors for dementia such as unskilled work and childhood trauma ${ }^{11}$. Longitudinal research into dementia risk in these communities is ongoing.

Australia has two culturally distinct First Nations populations, with 59,116 people, or $7.4 \%$ of the total Indigenous population, identified in 2016 as being of Torres Strait Islander descent $^{12}$. Traditionally of Melanesian origin, Torres Strait Islander people have their own distinctive culture and heritage, yet often lack recognition as being a separate and unique cultural group in Australia ${ }^{13}$. According to the 2016 census, 9,073 Torres Strait Islander peoples resided in the Torres Strait, within 18 island and 5 northern peninsula communities located between the tip of Cape York Peninsula in Queensland and Papua New Guinea ${ }^{14}$. Approximately 1,660 of these were aged 45 years and over ${ }^{5}$.

It is not known if Torres Strait Islander communities share the increased risk of dementia seen in Aboriginal communities, although high rates of midlife chronic disease such as hypertension and diabetes, which may increase dementia risk, are found in the Torres Strait ${ }^{15,16}$. Torres Strait Islander people also experience similar socioeconomic disadvantage and poorer health outcomes as Aboriginal Australians, with those living in the Torres Strait having similar levels of disadvantage as remote Aboriginal communities ${ }^{13}$. A recent pilot study suggested there may be some cause for concern, identifying four cases of CIND and one case of Dementia of the Alzheimer's type in 20 residents aged over 45 from Hammond Island in the Torres Strait ${ }^{17}$. Eighty percent of the sample, and all of those with cognitive impairment, had at least one vascular risk factor. Whilst generalisations to the wider Torres Strait were limited by the small sample size, this study highlighted the need for further 
research to establish the overall prevalence of dementia within the region. Accurate prevalence figures are critical for future planning and provision of appropriate care for people with dementia and their carers.

The aim of this study was to determine the prevalence of dementia across the wider Torres Strait region. Data on medical and lifestyle risk factors for dementia and associated problems of ageing such as incontinence, falls, and poor mobility, were also collected.

\section{Ethical Considerations}

The study was co-designed and conducted in partnership with the Post-Acute, Rehabilitation and Aged Care Service on Thursday Island. Ethics approval was obtained from Queensland Health (HREC/13/QCH/129-878) and James Cook University (H5495) Human Research Ethics Committees.

\section{Methods}

\section{Study Design}

The study was conducted across all 18 island and 5 mainland communities in the Torres Strait and Northern Peninsula Area to ensure the diversity of the region was captured. Data were collected over a three-year period between May 2015 and February 2018. The study used similar methodology to the Kimberley study ${ }^{6}$ so comparisons could be made across studies. Participants underwent a comprehensive health assessment using the Kimberley Indigenous Cognitive Assessment (KICA) ${ }^{18}$, which was administered by members of the research team. The KICA tool is a survey instrument that collects clinical information (social, medical, smoking/alcohol history, and depression/anxiety), functional status, and informant report. A cognitive screening tool (KICA-cog), embedded within the KICA tool, was also administered as part of a wider validation study. Data from this cognitive tool was not used in this study with results of the validation study to be reported elsewhere. The overall tool takes around 45 minutes to complete (30 minutes with the participant and 15 minutes with a carer). Participants also underwent a comprehensive geriatric assessment with a Geriatrician who was blinded to the results of the KICA tool. Geriatricians conducted a standard diagnostic medical examination assessing physical, cognitive, and psychosocial factors and used standardised screening tools, verbal fluency measures, and clock drawing as appropriate, and informant report where possible, as part of a global clinical assessment of cognition. Geriatricians involved in the study had many years of clinical experience in cross cultural 
dementia diagnoses and working with older adults living in remote Aboriginal and Torres Strait Islander communities, and were aware of limitations of standardised tools. Diagnoses were also reviewed by a consensus panel. Assessments were completed at the local primary health service or community hall depending upon community preference, with some participants choosing to be seen at home. One of the team members provided cultural and language support throughout.

\section{Participants}

Participants included Aboriginal and Torres Strait Islander adults aged 45 years and over residing in the Torres Strait and Northern Peninsula Area. There were no other specific inclusion or exclusion criteria as the aim of the study was to assess as many residents as possible. Similar recruitment strategies to those adopted in earlier studies in Aboriginal communities $^{6,10}$ were used, whereby health centre staff approached clients and members of the wider community to participate. This allowed for comparisons across studies and was chosen as other methods, such as using an electoral roll, are known to be less useful, as Aboriginal and Torres Strait Islander Australians are known to be underrepresented on the roll, particularly in remote regions ${ }^{19}$. In small Torres Strait communities, the health centre is a central hub in the community, involved in health promotion activities for all community members across the lifespan, so health centre staff know their communities and residents well.

Wider recruitment strategies using snowballing techniques were also conducted. As part of the community consultation process, the team presented to councils, aged care and health services, and community groups; ran community workshops; attended local community events; and participated in local talkback radio programs. Flyers were placed on community notice boards, council newsletters, local social media platforms, and in the local paper. Residents of the residential aged care facility located on Thursday Island were invited to participate in the study and were assessed at the facility.

Participants were given verbal and written information about the study and written consent was obtained. In cases where capacity to consent was deemed to be impaired but the person wished to participate, consent was also obtained from next of kin. Potential participants were advised that they could see the doctor even if they did not wish to participate in the study and any resident who attended the clinic asking to see the doctor was given an 
appointment.

\section{Measures}

De-identified data from the Geriatrician assessments were reviewed by a panel of Geriatricians and an Older Person Psychiatrist to obtain consensus diagnoses. Participants were diagnosed using Diagnostic and Statistical Manual for Mental Disorders, $4^{\text {th }}$ Edition (DSM IV-TR) criteria $^{20}$. Dementia subtypes were specified where possible. This information was used to classify people into three groups: normal cognition, dementia, and cognitive impairment no dementia (CIND), for the purposes of analyses in the study. The CIND group comprised participants who met DSM IV-TR criteria of Cognitive Disorder-NOS or Amnestic DisorderNOS, e.g. having cognitive decline but not meeting criteria for dementia as no significant ADL impact.

\section{Data analysis}

An a priori sample size calculation for the prevalence of dementia ${ }^{21,22}$ was performed based on 2011 Torres Strait Islander population estimates. The margin of error was set at 5\% and confidence intervals at $95 \%$. The expected prevalence of dementia was estimated at $12.4 \%$ based on the rate reported in the Kimberley study ${ }^{6}$. The calculation was corrected for a finite population estimate of 1,232 Torres Strait Islander residents aged 45 and over (i.e. $18.3 \%$ of the total 6,740 Torres Strait Islanders residing in the Torres Strait and Northern Peninsula region in 2011). With these parameters, a required sample size of 147 participants was calculated.

Crude prevalence rates of dementia for the sample were calculated using 10-year aged groups (starting from 45 years). These rates were then indirectly age standardised ${ }^{23}$ to 2016 estimates of the Australian prevalence of dementia for the same age groups. The national prevalence of dementia was calculated in two steps. The estimated number of Australians with dementia in 2016 was first obtained from the National Centre for Social and Economic Modelling (NATSEM) 2017 report $^{24}$. This number was then divided by the June 2016 population of Australia $^{25}$. This process allowed a comparison of the observed and expected number of dementia cases in the Torres Strait to calculate an age-standardised prevalence ratio.

Descriptive and inferential analyses were undertaken using SPSS Statistics for Windows, Version 26 (SPSS Inc., Chicago, Ill, USA). Associations between demographic variables 
(age, gender and education) were examined using independent samples t-tests and Pearson chi-square tests for independence.

\section{Results}

\section{Participants}

A total of 276 Aboriginal and/or Torres Strait Islander residents participated in the study. Of these, $88 \%$ were of Torres Strait Islander descent, $4 \%$ were of Aboriginal descent, and 8\% were of Aboriginal and Torres Strait Islander descent. A further 40 non-Indigenous residents in the Torres Strait also participated in the study and results for these participants are presented in Supplementary Table 1. Participants were recruited from all populated island and mainland communities in the Torres Strait, although due to small numbers in some communities, results are presented from the Torres Strait as a whole. When compared to 2016 census population estimates ${ }^{14}$, the sample represented $16.5 \%$ of Aboriginal and/or Torres Strait Islander residents in the Torres Strait region aged 45 and over.

The mean age of the sample was 65.1 years (SD10.8, range 45-93) and $34.4 \%$ were male. All had some formal education (33.1\% primary school only) and 33.2\% were working. There were no significant gender differences in age $(\mathrm{t}(274)=0.56, \mathrm{p}=.57)$ but a greater proportion of females had post-school education compared to males (41\% and $32 \%$ respectively), $\left(\mathrm{X}^{2}(3\right.$, $\left.\mathrm{N}=254)=10.12, \mathrm{p}=.018, \varphi_{\mathrm{c}}=.20\right)$. Torres Strait Kriol was the primary language spoken by $45.8 \%$ of the sample but $95 \%$ of participants spoke English as a primary or secondary language. Other local languages, Kala Lagaw La and Meriam Mir, were primary languages for $24 \%$ and $5 \%$ of the sample respectively. Demographic characteristics and selected health and behavioural measures of the sample are presented in Table 1.

\section{Dementia Prevalence}

Two participants were excluded from the analysis due to insufficient clinical information to make a diagnosis. Of the remaining 274 participants, 39 (14.2\%) were diagnosed with dementia and $60(21.9 \%)$ were diagnosed with Cognitive Disorder-NOS or Amnestic Disorder-NOS, according to DSM IV-TR criteria. Five participants diagnosed with dementia and 17 participants diagnosed with Cognitive Disorder-NOS or Amnestic Disorder-NOS were under 65 years of age. 
Dementia subtypes are shown in Table 2. The most common diagnosis was Dementia Not Otherwise Specified (38.5\%) followed by Dementia of the Alzheimer's Type (30.7\%) and Vascular Dementia (20.5\%). There were no cases of Alcohol-related Dementia and, consistent with research in Aboriginal communities ${ }^{6,10}$, alcohol use (past or current) was not a significant variable in the study.

The overall prevalence of dementia for the sample (14.2\%) was 4.0 times higher than the 2016 Australian prevalence (3.6\%) for the same age range (Table 3). Older participants were overrepresented in the sample, relative to the wider Australian age distribution. After accounting for this effect through indirect age standardisation, the sample prevalence of dementia was 2.87 times higher than the overall Australian population. The age specific rate ratio was pronounced for the 60-69-year group (4.4 times higher) with the gap narrowing with age to 2.21 times higher in those aged 80 and over.

\section{Health Status}

Vascular risk factors were identified in $95.6 \%$ of the sample and in $97 \%$ of those with diagnosed cognitive impairment. Over $79 \%$ of the sample had more than one vascular risk factor, and $36 \%$ of the sample had four or more risk factors. The number of vascular risk factors was significantly higher in people diagnosed with cognitive impairment $(M=3.27$, $\mathrm{SD}=1.4)$ compared to people who were cognitively normal $(\mathrm{M}=2.57, \mathrm{SD}=1.4),(\mathrm{t}(272)=$ 3.93, $\mathrm{p}=<.001, \mathrm{~g}=0.50)$. Rates of associated problems of ageing such as hearing impairment, reduced vision, pain, falls, reduced mobility, and incontinence were also high. Rates of polypharmacy ( 5 or more daily medications $)^{26}$ were present in $49.6 \%$ of the sample.

\section{Discussion}

This study extended the preliminary findings of the Hammond Island pilot study to identify an increased prevalence of dementia across the Torres Strait, with rates nearly three times higher than the general population being found. Results were broadly consistent with the three to five fold increased prevalence identified in Aboriginal communities ${ }^{6,10}$, despite different demographic and clinical characteristics and disparate geographical locations. As in Aboriginal communities, Dementia of the Alzheimer's type was the most frequently diagnosed subtype of dementia followed by Vascular Dementia. A high number of Dementia 
Not Otherwise Specified diagnoses reflected lack of access to local neuroimaging and accurate longitudinal clinical information.

The prevalence of dementia in the current study (14.2\%) was comparable to a similar study by Smith et al., ${ }^{6}$ in Aboriginal Australians (12.4\%). However, the age standardised prevalence ratio of 2.87 in the current study was lower than that reported by Smith et al., ${ }^{6}$ (i.e. 5.2). This reflects differences in national dementia estimates used for comparison, with the current study using a national estimate of 3.6\% among people age 45 years and over in 2016, while Smith et al., compared to a 2006 estimate of $2.4 \%{ }^{7}$. Nevertheless, these results show that Aboriginal and Torres Strait Islander people share an increased risk of dementia, and at an earlier age of onset than the wider community. Whether these communities share or have distinct patterns of risk factors is not yet clear, although analysis of specific risk factors for dementia within the current sample is underway.

The increased risk of dementia in younger age groups in the current study was consistent with other studies in Aboriginal communities, particularly the higher rate in those aged 60-69 years. Given the frequent delay in diagnosis reported in younger adults, these results highlight the need for education and training for health workers and clinicians around screening and assessment for dementia in younger adults living in Aboriginal and Torres Strait Islander communities. These results also highlight the need for services tailored to meet the specific needs of people with Younger Onset Dementia in the Torres Strait region.

Even though the dementia prevalence ratio narrowed with age, there was still more than double the risk of dementia in participants aged 80 and over. The prevalence of cognitive impairment within the over 80 age group, at $75 \%$ (including 50\% with dementia), is concerning given the high rates of medical comorbidities and problems of ageing identified. Further research is required to explore potential unmet needs of people with dementia and their families and types of services that people living in the Torres Strait would prefer.

Rates of chronic disease and other vascular risk factors were high, with all but three people with diagnosed cognitive impairment having at least one risk factor and most having multiple risk factors. This is consistent with the high rates of chronic disease previously reported in the Torres Strait ${ }^{15,16}$. These results highlight the overall health consequences of mid and late life vascular risk, suggesting that many Torres Strait residents may be at risk of cognitive 
decline. There were also high rates of comorbid problems associated with ageing such as falls risk, poor mobility, and incontinence that can significantly affect health and quality of life. Rates of polypharmacy were also high. Many of these issues are amenable to intervention, highlighting the importance of developing culturally appropriate screening and interventions to address the high rates of chronic disease and excess disability identified in the study. Given the high rates of comorbidities in the study, such interventions need to be targeted earlier in life, tailored for different developmental stages across the lifespan, to be most effective.

\section{Limitations}

The number of people recruited to the study was double the number estimated to adequately power the study. However, there were relatively few 'younger' participants aged 45-59 years, which limited the reliability of estimating the burden of Younger Onset Dementia in this population. For example, although the one case of dementia in the age group 50-59 years produced an age specific rate ratio of 10.99 compared to the Australian population, this rate would be too unstable for a valid comparison ${ }^{27}$. While the current results are suggestive of a substantial burden in younger age groups, this would need to be examined in further research. In our study, this is evident in the reduction of the Rate Ratio after standardisation, from 4.00 to 2.87 . The sample was also biased by a higher proportion of older participants, which does reduce the comparability to Smith et al. $^{6}$. However, both studies compare to the Australian population using Indirect Standardisation, which addresses the issue of age biased sampling. Whilst many of the recruitment strategies reached people within the broader community, participation may have been skewed by a self-selection bias, with those holding concerns about their cognition being more likely to agree to participate. The absence of neuroimaging data to inform diagnostic considerations is an acknowledged limitation within study and previous studies in Aboriginal communities. This reflects the lack of access to imaging, providing one example of the health inequalities experienced by remote communities. Furthermore, numbers were too small on some islands for sub analyses to be conducted to investigate differences within the region and males were underrepresented in this study, which may reflect a bias in recruitment from clinic lists, as men are shown to use health services less frequently than women ${ }^{28}$. The number of non-Indigenous participants was too small to make a meaningful examination. Whilst including non-Indigenous participants in the study may limit comparisons with previous research in Aboriginal specific populations, results from the main and sub-analyses were comparable. This suggests that Torres Strait Island residents share lifestyle factors increasing their dementia risk irrespective of their 
background, which may need to be taken into consideration when planning appropriate interventions and services for the region.

\section{Conclusion}

This study identified an increased prevalence of dementia and associated problems of ageing in the Torres Strait. Results can inform future planning and provision of appropriate care for people with dementia and their families living in the region. Findings highlight the need for culturally appropriate models of care to address risk factors and for health professionals to actively promote healthy lifestyles across the lifespan to reduce dementia risk.

\section{Impact Statement}

This study has found an increased prevalence of dementia in the Torres Strait at almost three times the rate seen in the wider community and impacting people at an earlier age. Results can inform future planning and provision of appropriate care for people with dementia and their carers.

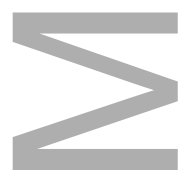

\section{References}

1. World Health Organization. World Report on Ageing and Health. Geneva: World Health Organization; 2015.

2. Dementia Australia. Dementia: Key facts and statistics 2018. https://www.dementia.org.au/files/documents/2018_Dementia_Key_facts\%2526stats. pdf. Published 2018. Accessed 01/03/20.

3. Australian Bureau of Statistics. Causes of Death, Australia, 2016. Cat. no. 3303.0. Canberra: ABS;2017.

4. Greenwood N, Smith R. The experiences of people with young-onset dementia: A meta-ethnographic review of the qualitative literature. Maturitas. 2016;92:102-109.

5. Australian Bureau of Statistics. Estimates and Projections, Aboriginal and Torres Strait Islander Australians, 2006 to 2031. Cat. No. 3238.0. Canberra: ABS;2019. 
6. Smith K, Flicker L, Lautenschlager NT, et al. High prevalence of dementia and cognitive impairment in Indigenous Australians. Neurology. 2008;71(19):1470-1473.

7. Australian Institute of Health and Welfare. Dementia in Australia: National Data Analysis and Development. Cat. No. AGE 53. Canberra: AIHW;2006.

8. Petersen RC, Lopez O, Armstrong MJ, et al. Practice guideline update summary: Mild cognitive impairment: Report of the Guideline Development, Dissemination, and Implementation Subcommittee of the American Academy of Neurology. Neurology. 2018;90(3):126-135.

9. Smith K, Flicker L, Dwyer A, et al. Factors associated with dementia in Aboriginal Australians. Australian and New Zealand Journal of Psychiatry. 2010;44(10):888893.

10. Radford K, Mack HA, Draper B, et al. Prevalence of dementia in urban and regional Aboriginal Australians. Alzheimer's \& Dementia. 2015;11(3):271-279.

11. Radford K, Lavrencic LM, Delbaere K, et al. Factors Associated with the High Prevalence of Dementia in Older Aboriginal Australians. Journal of Alzheimer's Disease. 2019;70(s1):S75-S85.

12. Australian Bureau of Statistics. Census of Population and Housing-Counts of Aboriginal and Torres Strait Islander Australians, 2016. Cat. No. 2075.0. Canberra: ABS;2017.

13. Dudgeon P, Milroy H, Walker R, et al. Working together: Aboriginal and Torres Strait Islander Mental Health and Wellbeing Principles and Practice. 2nd ed. Canberra: Department of the Prime Minister and Cabinet; 2014.

14. Australian Bureau of Statistics. Changing Characteristics of the Torres Strait Region and its People, 2011 to 2016. Cat 4738.0. Canberra: ABS;2018.

15. Leonard D, McDermott R, O'Dea K, et al. Obesity, diabetes and associated cardiovascular risk factors among Torres Strait Islander people. Australian and New Zealand Journal of Public Health. 2002;26(2):144-149.

16. O'Dea K. Preventable chronic diseases among indigenous australians: the need for a comprehensive national approach. Heart, Lung and Circulation. 2005;14(3):167-171.

17. Russell S, Strivens E, LoGiudice D, Smith K, Helmes E, Flicker L. Ageing on Hammond Island: Is there cause for concern in the Torres Strait? Australian Journal of Rural Health. 2016;24(5):342-343. 
18. Smith K, Flicker L, Almeida OA, et al. The Kimberley Indigenous Cognitive Assessment (KICA): Results of reliability and validity in an Indigenous population. Internal Medicine Journal. 2005;35(35):A47-A62.

19. The Parliament of the Commonwealth of Australia. Civics and Electoral Education Parliament of Australia Joint Standing Committee on Electoral Matters. Canberra: Author;2007.

20. American Psychiatric Association. Diagnostic and Statistical Manual of Mental Disorders (4th Ed., Text Revision). Washington, DC: Author; 2000.

21. Arya R, Antonisamy B, Kumar S. Sample size estimation in prevalence studies. Indian Journal of Pediatrics. 2012;79(11):1482-1488.

22. Kasiulevičius V, Šapoka V, Filipavičiūtė R. Sample size calculation in epidemiological studies. Gerontologija. 2006;7(4):225-231.

23. Australian Bureau of Statistics. Principles on the use of direct age-standardisation in administrative data collections: for measuring the gap between Indigenous and nonIndigenous Australians. Cat. no. CSI 12. Canberra: ABS;2011.

24. Brown L, Hansnata E, Anh La H. Economic Cost of Dementia in Australia 20162056. Report Prepared for Alzheimer's Australia. Canberra: NATSEM at the Institute for Governance and Policy Analysis, University of Canberra;2017.

25. Australian Bureau of Statistics. Australian Demographic Statistics, June 2016. Cat No. 3101.0. Canberra: ABS;2016.

26. Masnoon N, Shakib S, Kalisch-Ellett L, Caughey GE. What is polypharmacy? A systematic review of definitions. BMC Geriatrics. 2017;17(1):230-230.

27. Australian Institute of Health and Welfare. Cancer statistics for small geographic areas: user guide and methods manual. Cat. no. CAN 108. Canberra: AIHW;2019.

28. Smith JA, Braunack-Mayer A, G. W. What do we know about men's help-seeking and health service use. Medical Journal of Australia. 2006;184(2):81-83.

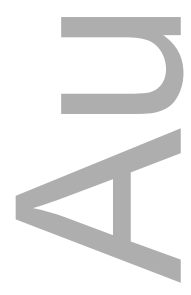


Table 1. Demographic characteristics and selected health and behavioural measures of 274 Aboriginal and/or Torres Strait participants according to Diagnostic and Statistical Manual of Mental Disorders (DSM IV-TR) diagnosis, May 2015 - February 2018.

\begin{tabular}{|c|c|c|c|c|}
\hline Variable & $\begin{array}{c}\text { Normal } \\
\text { cognition n }(\%)\end{array}$ & $\begin{array}{l}\text { CIND } \\
\mathrm{n}(\%)\end{array}$ & $\begin{array}{c}\text { Dementia } \\
\text { n }(\%)\end{array}$ & $\begin{array}{l}\text { Total } \\
\mathrm{N}(\%)\end{array}$ \\
\hline Total & $175(63.9 \%)$ & $60(21.9)$ & $39(14.2)$ & $274(100)$ \\
\hline \multicolumn{5}{|l|}{ Age $\square$} \\
\hline $45-49$ & $17(9.7)$ & $2(3.3)$ & $0(0)$ & $19(6.9)$ \\
\hline $50-54$ & $33(18.9)$ & $2(3.3)$ & $0(0)$ & $35(12.8)$ \\
\hline $55-59$ & $31(17.7)$ & $2(3.3)$ & $1(2.6)$ & $34(12.4)$ \\
\hline $60-64$ & $35(20)$ & $11(18.3)$ & $4(10.3)$ & $50(18.2)$ \\
\hline $65-69$ & $27(15.4)$ & $12(20)$ & $7(17.9)$ & $46(16.8)$ \\
\hline $70-74$ & $12(6.9)$ & $11(18.3)$ & $8(20.5)$ & $31(11.3)$ \\
\hline $75-79$ & $13(7.4)$ & $13(21.7)$ & $5(12.8)$ & $31(11.3)$ \\
\hline $80+$ & $7(4)$ & $7(11.7)$ & $14(35.9)$ & $28(10.2)$ \\
\hline \multicolumn{5}{|l|}{ Gender } \\
\hline Male & $60(34.3)$ & $20(33.3)$ & $14(35.9)$ & $94(34.3)$ \\
\hline Female & 115 (65.7) & $40(66.7)$ & $25(64.1)$ & $180(65.7)$ \\
\hline \multicolumn{5}{|l|}{ Schooling } \\
\hline Primary & $40(23.4)$ & $29(53.7)$ & $13(48.1)$ & $82(32.5)$ \\
\hline Grade $8-10$ & $41(24)$ & $7(13)$ & $8(29.6)$ & $56(22.2)$ \\
\hline Grade $11-12$ & $13(7.6)$ & $3(5.6)$ & $2(7.4)$ & $18(7.1)$ \\
\hline Post school & $77(45)$ & $15(27.8)$ & $4(14.8)$ & $96(38.1)$ \\
\hline \multicolumn{5}{|c|}{ Self-reported behaviours } \\
\hline Current alcohol & $56(32.6)$ & $10(17.5)$ & $2(5.6)$ & $68(25.7)$ \\
\hline Previous alcohol & $134(78.4)$ & $37(64.9)$ & $17(48.6)$ & $188(71.5)$ \\
\hline Current smoker & $28(16.3)$ & $9(15.8)$ & $4(11.1)$ & $41(15.5)$ \\
\hline Ex-smoker & $124(72.9)$ & $37(68.5)$ & $19(65.5)$ & $180(71.1)$ \\
\hline \multicolumn{5}{|c|}{ Self-reported medical history } \\
\hline Poor vision & $30(17.6)$ & $12(22.6)$ & $10(31.3)$ & $52(20.4)$ \\
\hline Poor hearing & $21(12.4)$ & $7(13.2)$ & $5(15.6)$ & $33(13)$ \\
\hline
\end{tabular}




$\begin{array}{lcccc}\text { Pain } & 86(50.6) & 15(28.3) & 10(32.3) & 111(43.7) \\ \text { Falls } & 27(15.9) & 16(30.8) & 4(13.3) & 47(18.7) \\ \text { Poor mobility } & 39(22.9) & 22(41.5) & 17(54.8) & 78(30.7) \\ \text { Incontinence } & 45(26.5) & 12(22.6) & 10(32.3) & 67(26.4) \\ \text { Head injury } & 31(18.6) & 9(17.3) & 4(15.4) & 44(18)\end{array}$

\section{Medical History from Geriatrician}

\begin{tabular}{lcccc} 
One or more & $166(94.9)$ & $58(96.7)$ & $38(97.4)$ & $262(95.6)$ \\
vascular risk factor & & & & \\
Hypertension & $106(60.6)$ & $43(71.7)$ & $28(71.8)$ & $177(64.6)$ \\
Diabetes & $103(58.9)$ & $38(63.3)$ & $30(76.9)$ & $171(62.4)$ \\
Dyslipidaemia & $66(37.7)$ & $28(46.7)$ & $23(59)$ & $117(42.7)$ \\
Heart disease & $24(13.7)$ & $15(25)$ & $10(25.6)$ & $49(17.9)$ \\
Chronic Kidney & $22(12.6)$ & $18(30)$ & $15(38.5)$ & $55(20.1)$ \\
$\begin{array}{l}\text { Disease } \\
\text { Cerebrovascular }\end{array}$ & $4(2.3)$ & $3(5)$ & $12(30.8)$ & $19(6.9)$ \\
Disease & $1(0.6)$ & $0(0)$ & $2(5.1)$ & $3(1.1)$ \\
Epilepsy & $62(40.5)$ & $38(63.3)$ & $24(63.2)$ & $124(49.4)$ \\
Polypharmacy & & & & \\
\hline
\end{tabular}

Note: CIND = Cognitive Impairment Not Dementia [Cognitive-NOS and Amnestic NOS combined] Polypharmacy $=5$ or more prescription medications

Health and behavioural measures based on self-report data obtained from the KICA tool and medical history obtained from Geriatrician assessment

Vascular risk factors were defined as self-reported smoking, diabetes, hypertension, dyslipidaemia, heart disease, cerebrovascular disease, or chronic kidney disease. 
Table 2

Dementia subtypes in 39 participants diagnosed with dementia, according to the Diagnostic and Statistical Manual of Mental Disorders (DSM IV), May 2015 - February 2018

\begin{tabular}{lc}
\hline DSM IV Diagnosis & $\mathrm{n}(\%)$ \\
\hline Dementia not otherwise specified & $15(38.5)$ \\
Dementia of the Alzheimer's Type & $12(30.7)$ \\
Vascular Dementia & $8(20.5)$ \\
Dementia due to other general medical & $3(7.7)$ \\
condition & \\
Dementia due to multiple etiologies & $1(2.6)$ \\
\hline
\end{tabular}

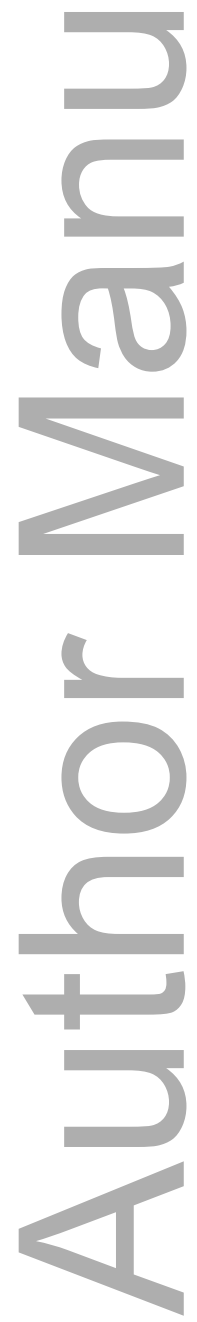




\section{Table 3}

Dementia prevalence and indirectly age standardised prevalence ratio for 274 Aboriginal and/or Torres Strait residents, May 2015 - February 2018

\begin{tabular}{|c|c|c|c|c|c|c|c|c|c|c|c|c|}
\hline \multirow{3}{*}{ Age groups } & \multicolumn{4}{|c|}{ Torres \& NPA } & \multicolumn{4}{|c|}{ Australia (2016) } & \multicolumn{4}{|c|}{ Torres \& NPA } \\
\hline & \multirow{2}{*}{$\underset{n}{\frac{\text { Total }}{n}} \frac{\text { Normal }}{n}$} & \multirow{2}{*}{$\frac{\mathrm{MCl}}{\mathrm{n}}$} & \multicolumn{2}{|c|}{ Dementia } & \multirow[b]{2}{*}{$(95 \% \mathrm{Cl})$} & \multirow{2}{*}{$\frac{\text { Population }}{n^{1}}$} & \multicolumn{2}{|c|}{ Dementia } & \multirow{2}{*}{$\begin{array}{l}\text { Unstandardised } \\
\text { Prevalence Ratio O }\end{array}$} & \multicolumn{3}{|c|}{ Age standardised prevalence } \\
\hline & & & $n$ & Prevalence & & & $\mathrm{N}^{2}$ & Prevalence & & bserved (n) & Expected (n) & Ratio \\
\hline $45-49^{*}$ & $19 / 17$ & 2 & 0 & $0.0 \%$ & $(0.0-0.0)$ & $3,230,064$ & 749 & $0.0 \%$ & 0.00 & 0 & 0.0 & 0.00 \\
\hline 50-59 & $69 \quad 64$ & 4 & 1 & $1.4 \%$ & $(-1.4-4.3)$ & $3,022,101$ & 3,986 & $0.1 \%$ & 10.99 & 1 & 0.1 & 10.99 \\
\hline $60-69$ & $9 6 \longdiv { 6 2 }$ & 23 & 11 & $11.5 \%$ & $(5.1-17.8)$ & $2,498,141$ & 65,051 & $2.6 \%$ & 4.40 & 11 & 2.5 & 4.40 \\
\hline 70-79 & 62 & 24 & 13 & $21.0 \%$ & $(10.8-31.1)$ & $1,553,615$ & 116,728 & $7.5 \%$ & 2.79 & 13 & 4.7 & 2.79 \\
\hline $80+$ & $28 \quad 7$ & 7 & 14 & $50.0 \%$ & $(31.5-68.5)$ & 944,719 & 214,168 & $22.7 \%$ & 2.21 & 14 & 6.3 & 2.21 \\
\hline Total (45+) & $274 \quad 175$ & 60 & 39 & $14.2 \%$ & $(10.1-18.4)$ & $11,248,640$ & 400,682 & $3.6 \%$ & 4.00 & 39 & 13.6 & 2.87 \\
\hline
\end{tabular}

Notes: *45-49 for Torres Strait Islander participants, $40-49$ for the Australia 2016 sample.

1. Australian Bureau of Statistics. Australian Demographic Statistics, Jun 2016. Cat. NO. 3101.0. Canberra: ABS; 2016. Data Cube: Population by Age and Sex. Table 8. Viewed 30/11/2019 <https://www.abs.gov.au/AUSSTATS/abs@.nsf/DetailsPage/3101.0Jun\%202016?OpenDocument>

2. Brown L, Hansnata E, Anh La H. Economic Cost of Dementia in Australia 2016-2056. Report Prepared for Alzheimer's Australia. Canberra:

The Institute for Governance and Policy Analysis, University of Canberra; 2017.

This article is protected by copyright. All rights reserved 


\section{University Library}

\section{- M M N E R VA A gateway to Melbourne's research publications}

Minerva Access is the Institutional Repository of The University of Melbourne

\section{Author/s:}

Russell, SG;Quigley, R;Thompson, F;Sagigi, B;LoGiudice, D;Smith, K;Pachana, N;Miller, G;Strivens, E

Title:

Prevalence of dementia in the Torres Strait

Date:

2020-11-10

\section{Citation:}

Russell, S. G., Quigley, R., Thompson, F., Sagigi, B., LoGiudice, D., Smith, K., Pachana, N., Miller, G. \& Strivens, E. (2020). Prevalence of dementia in the Torres Strait. AUSTRALASIAN JOURNAL ON AGEING, 40 (2), pp.E125-E132. https://doi.org/10.1111/ajag.12878.

Persistent Link:

http://hdl.handle.net/11343/276596 